\section{A. ARS BILDUMA \\ ISSN 1989-9262 \\ UPV/EHU Press}

ARSBILDUMA (CC BY-NC-ND 4.0)

https://doi.org/10.1387/ars-bilduma.20532 BIBLID [(2020), 10; 37-47]

Recibido: 19/01/2019 Aceptado: 15/09/2019

\section{GUADALUPE ROMERO SÁNCHEZ}

Universidad de Granada

Facultad de Ciencias de la Educación

Departamento de Didáctica de las Ciencias Sociales

Campus Universitario de Cartuja s/n

18071 Granada (Granada)

guadalupers@ugr.es

https://orcid.org/0000-0003-3865-3579

Proyecto I+D+i "Relaciones entre Andalucía y América. Los territorios periféricos: Estados Unidos y Brasil. HAR2017-83545-P", Ministerio de Economía, Industria y Competitividad, dirigido por el catedrático de Historia del Arte de la Universidad de Granada Rafael López Guzmán.

\title{
DEVOCIÓN Y PODER. LEGADOS TRANSOCEÁNICOS A CON- VENTOS CARMELITAS ANDALUCES
}

\author{
DEVOTION AND POWER. TRANSOCEANIC LEGACIES TO THE ANDALUSIAN \\ CARMELITES CONVENTS
}

\author{
DÉVOTION ET PUISSANCE. LES HÉRITAGES TRANSOCÉANIQUES AUX COU- \\ VENTS DES CARMES ANDALOUS
}

RESUMEN

En el marco de las relaciones culturales y transferencias artísticas que se sucedieron a lo largo de los siglos XVI al XVIII entre Andalucía y América, una parcela importante la constituyen las labores de mecenazgo y coleccionismo de obras de arte. En esta línea de trabajo, centramos nuestra investigación en el análisis de las donaciones realizadas por algunos indianos a conventos y monasterios carmelitas de sus ciudades de origen a través del análisis documental, presentando para ello materiales, en su mayoría inéditos, que nos ayudan a comprender este tipo de legados.

\section{PALABRAS CLAVE}

Legado artístico; indianos; Juan de la Torre; Damián Ruiz de Salazar; Pedro Galera; convento del Santo Ángel Custodio; convento de San José; convento de los Santos Mártires.

\section{ABSTRACT}

Concerning the cultural relations and artistic transfer that took place from the 16th to the 18th centuries between Andalusia and America, an important part includes works of patronage and the colleting of works of art. We focus our investigation on the analysis of the donations made by some Indians to Carmelita Convents and Monasteries of their origin cities, through documentary analysis, presenting for it materials mostly unpublished, that help us to understand this kind of legacies.

\section{KEYWORDS}

Artistic legacy; Indians; Juan de la Torre; Damian Ruiz de Salazar; Pedro Galera; convent of Santo Ángel Custodio; convent of San José; convent of the Holy Martyrs.
RÉSUMÉ

Dans le cadre des relations culturelles et des transferts artistiques qui se sont déroulés du XVIe au XVIII siècle entre l'Andalousie et l'Amérique, une facette importante est constituyé par les oeuvres de mécénat et le collectionisme d'oeuvres d'art. Dans cette ligne de travail, nous concentrons nos recherches sur l'analyse des donations faits par certains Indiens à des couvents et monastères carmélites dans leur ville d'origine par le biais d'une analyse documentaire présentant des documents, pour la plupart inédits, qui nous aident à comprendre ce genre d'héritage.

\section{MOTS-CLÉS}

Héritage artistique; Indiens; Juan de la Torre; Damián Ruiz de Salazar; Pedro Galera; couvent de Santo Angelo Custodio; couvent de San José; couvent de Santos Mártires. 


\section{MARCO ESPACIO-TEMPORAL}

Las relaciones artísticas y comerciales entre Andalucía y América comenzaron en el mismo momento en que se dio inicio a la empresa americana, favorecidas por el establecimiento de la Casa de Contratación (1503-1785) como institución de fiscalización y control y por la regularización del tráfico marítimo a través de un sistema de flotas que quedaría fijado definitivamente en 1564. El trasiego constante y cada vez más intenso de personas y mercancías a través del Atlántico cimentaron unas relaciones privilegiadas entre los puertos andaluces, Sevilla y posteriormente Cádiz, y el mundo americano en las que las transferencias culturales y los intercambios artísticos anduvieron caminos de ida y vuelta ${ }^{1}$

Desde Andalucía, por ejemplo, partiría un considerable número de obras que, desde los dinámicos talleres sevillanos, se distribuyeron a lo largo y ancho de los virreinatos, contribuyendo a la formación de ese gusto artístico virreinal, entre los que es preciso mencionar los obradores de Juan Martínez Montañés y Francisco de Zurbarán. Los pioneros trabajos de Diego Angulo y Enrique Marco Dorta destacaron fundamentalmente porque localizaron y estudiaron las obras de estos artistas en América, concretamente en Guatemala y Honduras el primero, en Colombia y Venezuela el segundo. Ambos iniciaron una línea de investigación sumamente fructífera que fue continuada ya en la década de los años 1980 y 1990 por investigadores de la talla de Jorge Bernales Ballesteros, quien se centró en la escultura andaluza existente en el virreinato del Perú, y Juan Miguel Serrera Contreras dedicado al arte de la pintura y, concretamente, al papel preeminente que tuvo el obrador de Francisco de Zurbarán en el comercio artístico indiano ${ }^{2}$. Del mismo modo muchos

ROMERO SÁNCHEZ, G.: “Tesoros viajeros. Mecenazgo y coleccionismo artísticos en Andalucía”, Desde América del Sur. Arte virreinal en Andalucía. Catálogo de la Exposición. Granada, Proyecto MUTIS, 2017, pp. 47-50

2 Su estela en la historiografía andaluza actual se ha diversificado y son varios los grupos de investigación y los especialistas que continúan profundizando en esta temática. En la Universidad Hispalens tres grupos de investigación trabajan los temas relacionados con los artistas y obras de ascendenci andaluza que se conservan en América. Son los grupos "Laboratorio de Arte", "Fuentes para la historia del Arte Andaluz" y "LARAÑA" con investigadores como Alfredo Morales, Jesús Palomero, Alfonso Pleguezuelo y José María Sánchez Sánchez. Por su parte en la Universidad Pablo de Olavide destaca el grupo "Quadratura" dirigido por Fernando Quiles. También esta línea está presente en el grupo de el grepo "Q "A dać coranad con el investigador Rafael Lopez Guzman. Por otro lado, la Escuela de Estudios Hispanoamericanos perteneciente al Consejo Superior de Investigaciones Científicas, con el grupo de investigación "An dalucía y América: relaciones, influencia e intercambios", se ocupa de las relaciones artísticas que aqui artistas andaluces embarcarían para trabajar al otro lado del Atlántico como ocurrió con los sevillanos Gaspar de la Cueva y Andrés de la Concha o el granadino Francisco Gómez de Valencia entre otros muchos, especialmente en los momentos iniciales de la configuración del territorio influyendo de manera decisiva en la conformación de los centros artísticos autóctonos, los cuales, posteriormente, irán contando con creadores locales capaces de satisfacer los gustos de las sociedad virreinal ya plenamente establecida ${ }^{3}$.

No obstante, a pesar de la amplitud de esta temática y ligado a esa circulación de obras de arte y de artistas hay que vincular las actuaciones llevadas a cabo por personajes andaluces vinculados a otros sectores en suelo americano. Algunos de ellos ejercieron una poderosa influencia en el marco social en el que vivieron, hablamos principalmente de virreyes, de altos dignatarios eclesiásticos y de algunos nobles, que dejaron patente su gusto por determinados programas arquitectónicos, decorativos e iconográficos. Este es el caso de algunos andaluces como el virrey Matías Gálvez y Gallardo, fray Alonso de Montúfar, fray Juan de los Barrios o la Marquesa de San Jorge doña María Thadea González, estableciendo vínculos ideológicos de lo que es preciso que dejemos constancia en la formación del patrimonio americano ${ }^{4}$.

Ahora bien, si nos centramos en el estudio del mecenazgo y el coleccionismo podemos comprobar como las investigaciones sobre el retorno de los andaluces se ha considerado un cuestión de menor relevancia en el campo histórico-artístico. Más bien, las investigaciones han girado en torno a los personajes más relevantes, a identificar los objetos artísticos americanos existentes en Andalucía sin analizar normalmente la trayectoria de sus donantes o de sus donaciones, aunque hay excepciones muy interesantes que se abren al ámbito familiar o doméstico. Es el análisis del comportamiento de estos indianos a veces retornados, y que ocuparon puestos de segunda línea o menor nivel de importancia, donde localizamos una enorme cantidad de documentación de interés para el tema que nos ocupa.

nos interesan. Sobre el panorama de la investigación andaluza sobre el patrimonio artístico americano véase LÓPEZ GUZMÁN, R. y ESPINOSA SPİNOLA, G.: América con tinta andaluza. Historia del arte e historiografía. Almería, Servicio de Publicaciones de la Universidad de Almería, 2013.

3 MORALES MARTÍNEZ, A. J.: "Presencia del arte barroco mexicano en Andalucía", Andalucía y Améri ca. Cultura artística. LÓPEZ GUZMÁN, R. (coord.), Granada, Editorial Atrio, pp.13-29.

4 Algunos estudios de interés sobre esta temática son: RUIZ GUTIÉRREZ, A.: Fray Alonso de Montúfar: Loja y la formación de la iglesia indiana. Granada, Fundación Ibn al-Jatib de estudios y cooperación cultural, 2007; MORALES FOLGUERA, J. M.: "Los Gálvez de Macharaviaya y la ilustración americana" Andalucía-América. Estudios artísticos y culturales. LÓPEZ GUZMÁN, R. (coord.). Granada, Editorial 
Centrándonos en estos personajes es de reseñar que su partida hacia América, con destino a ocupar los puestos más diversos en la vida política, militar, religiosa o administrativa de los virreinatos, entre otros sectores, no impidió que siguieran vinculados con sus familias y con sus lugares de origen, más bien su marcha potenció en algunos aspectos dichos vínculos, como muestra la documentación relacionada, siendo un aspecto como se verá de enorme importancia. Así, no solo se afianzaban estos lazos familiares, con una imagen muy extensa de los mismos, sino que se creaban otros de interés comercial o económico e incluso relaciones de servidumbre que facilitaban que no solamente se beneficiaran de los éxitos obtenidos en Indias las personas que pasaban físicamente hacia el continente sino también todo un entramado de sujetos que, por diferentes razones, pasaban a depender de ellos, aspecto muy llamativo en el caso de los virreyes o de los obispos ${ }^{5}$ pero también rastreables en personas de menor rango.

De las múltiples actuaciones llevadas a cabo por los indianos andaluces nos interesan aquellas acciones que tienen que ver con el retorno de parte de su fortuna y con el destino de algunos de sus bienes más preciados. Para ello es muy útil el análisis de la documentación de archivo, especialmente de los fondos notariales, pues en los testamentos, mandas testamentarias, expedientes de últimas voluntades y bienes de difuntos, encontramos gran cantidad de datos acerca del procedimiento seguido por éstos y que es muy similar en la mayoría de los casos. Así, para el tema que nos interesa, podemos establecer dos grupos de indianos que realizan donaciones: aquellos andaluces que testan en suelo americano dejando instrucciones precisas para que sus albaceas acaten sus deseos; y los retornados con cierto capital, que gestionan su fortuna antes de establecer su testamento. Esto se traduce en donaciones; fundaciones de mayorazgos; concertación de cartas de dote; envíos de dinero, artículos de platería y bienes de muy diversa índole, entre otras acciones, que tenían como destino, por un lado, engrandecer el linaje familiar como es el caso de don Luis Pérez Navarro en Granada o de los Marín de Poveda en Almería ${ }^{6}$, y por otro, dejar

de la Universidad de Granada y Atrio, 2010, pp. 111-135; MONTES GONZÁLEZ, F.: Mecenazgo virreina y patrocinio artístico. El ducado de Alburquerque en la Nueva España. Sevilla, Real Maestranza de Caballería de Sevilla, 2016; RODRÍGUEZ MOYA, I.: La mirada del Virrey. Castellón, Universidad Jaume I, 2003.

5 DEDIEU, J. P.: "El séquito de los obispos que pasaron a Indias en la primera mitad del siglo XVIII", Hal. Archives-Ouvertes 2006, http//halchs archives-ouvertes fr/halchs-00105935 (consulta 5 de Abril de 2017).

- ROMERO SÁNCHEZ G. y ESPINOSA SṔNOLA, G. "El mecenazgo indino en Andlucia orenta

el caso de don Luis Perez Navarro, Arte y patrimonio en Iberoamérica. Trficos transoceanicos. RODR GUEZ MOYA, I., FERNÁNDEZ VALLE, M. A. y LÓPEZ CALDERÓN, C (coords). Castellón, Servicio de Publicaciones de la Universitat Jaume I, 2016, pp. 233-253. LÓPEZ GUZMÁN, R. y ROMERO SÁN constancia de su memoria y agradecer en lo espiritual su suerte y fortuna. Este segundo caso se constata en la fundación de innumerables capellanías; en la adquisición y renovación de capillas, que además había que adornar y dotar; en la fundación de hospitales y un largo etcétera de obras pías, entre otras actuaciones menos numerosas. Actuaciones que se dan mayoritariamente a lo largo del siglo XVII, aunque no exclusivamente, coincidente con el momento culmen de la arquitectura conventual, al menos en Andalucía oriental.

Algunos ejemplos de donación de obras de arte a iglesias o conventos andaluces los encontramos en Alonso González de la Pava, quien después de hacer fortuna en Potosí extrayendo plata, fundó el convento y hospital del Espíritu Santo en Guadalcanal (Sevilla) y del que podemos contemplar su retrato ; Alonso de Cañete, clérigo establecido en Perú, que fundará una capellanía en Aguilar (Córdoba) su pueblo natal'; el capitán Francisco Cano del Hierro, natural de Cazalla de la Sierra (Sevilla), quien en su testamento fechado en Cuzco solicita que sus herederos donen un considerable número de obras de plata a la iglesia de Nuestra Señora de la Concepción de su localidad; García Jiménez Franco que, siendo natural de Villalba del Alcor (Huelva), fundará el convento de San Juan Bautista dotando a la comunidad beneficiada además con una gran cantidad de bienes ${ }^{10}$; José Bernardo de León Carvajal, hermano del racionero de la catedral hispalense Félix de León, quién envió a mediados del siglo XVII una lámpara de plata a la capilla real sevillana, con

CHEZ, G. "El Convento de San Antón y el Mecenazgo Indiano", Entre Ríos. Revista de Arte y Letras, Vol. 21-22, 2014. Número temático: Ora et Labora. Conventos Granadinos, pp. 98-108. ESPINOS SPÍNOLA, G. y ROMERO SÁNCHEZ, G.: "Riquezas de Indias en Andalucía: poder, dinero y promoción artística. Aproximación a un estado de la cuestión”. La formación artística: creadores - historiadores - espectadores. XXI Congreso Nacional de Historia del Arte. ALONSO RUIZ, B; POLO SÁNCHEZ, J. y SAZATORNIL RUIZ L (coords). Santander Editorial Universidad de Cantabria, 2018 , pp. 1421-1432.

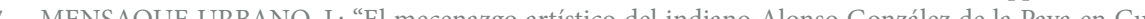
dalcanal". Actas de las III Jornadas de Andalucía y América. Baeza, Universidad Internacional de Andalucía, pp. 59-79.

GARCÍA-ABASOLO GONZÁLEZ, A. F.: "Inversiones indianas en Córdoba. Capellanías y patronatos como entidades financieras". Actas II Jornadas de Andalucía y América. Andalucía y América, siglo XVI TORRES RAMÍREZ, B. y HERNÁNDEZ PALOMO, J. J. (coords). Huelva, La Rábida, 1982. Tomo 2, pp. 443-444.

9 ESTERAS MARTÍN, C.: "Nuevas aportaciones a la historia de la platería andaluza-americana". Actos III Jornadas de Andalucía y América, Andalucía y América, siglo XVII. TORRES RAMÍREZ, B. y HERNÁNDEZ PALOMO, I. J. (coords). Huelva, La Rábida, 1985. Tomo 2, pp. 35-36.

10 GONZÁLEZ GÓMEZ, J. J.: "El convento de San Juan Bautista de Villalba del Alcor, una fundación indiana de 1618". Actas III Jornadas de Andalucía y América, Andalucía y América, siglo XVII. TORRES RAMÍREZ, B. y HERNÁNDEZ PALOMO, J. J. (coords). Huelva, La Rábida, 1985. Tomo 2, pp. 81-96. 
destino a la Virgen de los Reyes ${ }^{11}$; al ya mencionado Luis Pérez Navarro, que habiendo sido religioso en Quito, donará una custodia que hoy sigue conservándose en la Basílica de Nuestra Señora de las Angustias en Granada, originalmente destinada a Terque (Almería), su pueblo natal o Cristóbal de Cerdio Martínez, quien donará un conjunto importante de piezas de plata a la iglesia de San Juan Bautista de Chiclana de la Frontera (Cádiz) ${ }^{12}$, que desgraciadamente no se conservan. Estos ejemplos son una mínima parte de la presencia real de piezas existentes en nuestra comunidad y menos aún de las numerosas referencias documentales que hay al respecto que demuestran el intenso tránsito de obras de arte y dinero desde sur de América a Andalucía, quedando aún por estudiar el alcance real que estas donaciones y partidas monetarias tuvieron para el desarrollo de nuestra comunidad en la época moderna

2. LOS LEGADOS DE DAMIÁN RUIZ DE SALAZAR Y PEDRO GALERA A LOS CONVENTOS CARMELITAS DE DE LA CIUDAD DE GRANADA

El convento carmelita de San José fue fundado en 1582 por Ana de Jesús, compañera de toda confianza de Santa Teresa, por imposibilidad de hacerlo directamente la propia reformadora ${ }^{13}$. A su llegada a Granada se establecieron en la calle Elvira, pero a partir de 1590 se mudaron a su actual emplazamiento, en el barrio del Realejo, al adquirir las casas pertenecientes a los duques de Sessa, descendientes del Gran Capitán. El viejo y ruinoso edificio debió ser reedificado en la segunda década del siglo XVII, inaugurándose el 15 de abril de 1629 bajo la advocación de San José. El templo, de una sola nave, sigue la estructura sencilla y sobria propia de la orden, aspecto que sigue conservando hoy (Figs. 1 y 2).

11 QUILES GARCÍA, F.: Sevilla y América en el barroco. Comercio, ciudad y arte. Sevilla, Bosque de Palabras, 2009, pp. 88.

12 ESPINOSA SPÍNOLA, G. y ROMERO SÁNCHEZ, G.: "Riquezas de Indias en Andalucía: poder, dinero y promoción artística. Aproximación a un estado de la cuestión". La formación artística: creadores - historiadores - espectadores. XXI Congreso Nacional de Historia del Arte. ALONSO RUIZ, B; POLO SÁNCHEZ, J. y SAZATORNIL RUIZ. L. (coords). Santander, Editorial Universidad de Cantabria, 2018, pp. 1421-1432.

13 GÓMEZ-MORENO CALERA, J. M.: La arquitectura religiosa granadina en la crisis del Renacimiento (1560-1650). Monografía Arte y Arqueología, Vol. 4. Granada, Universidad de Granada y Diputación Provincial de Granada, 1989, pp. 230

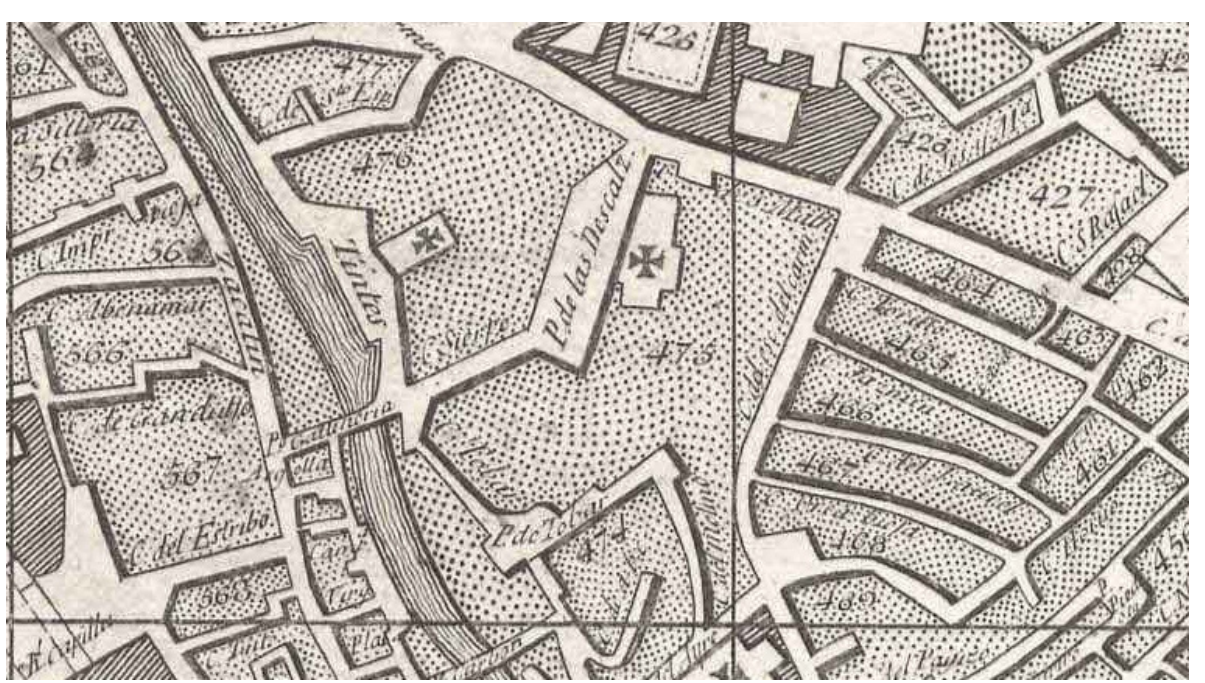

ig. 1: Detalle del emplazamiento del convento de San José de Granada del plano de Dalmau grabado por Ribera en 1796. ๑ Ayuntamiento de Granada, Archivo Municipal de Granada

Es llamativo cómo al poco tiempo de la compra de las viviendas que se adaptaron como primer convento de monjas carmelitas se recibiera la que pensamos sería la primera donación realizada por un indiano al mismo. Nos referimos a Damián Ruiz de Salazar, hijo de Francisco Ruiz de Salazar y de Francisca de la Torre, quien, en su testamento, firmado en Cuzco el 15 de septiembre de $1598^{14}$, haría una mención especial al mismo, destinando una parte pequeña de sus bienes. Así, según se desprende de la documentación este Ruiz de Salazar donará un total de 3.550 ducados para diferentes fines a la ciudad de Granada aunque la mayoría con destino a sus familiares y parientes: Juan Ruiz de Salazar, María de la Torre, Ana de la Torre, Guiomar López, María Ruiz de Salazar e Isabel de Soria. Igualmente donará 25 marcos de plata con la orden de que con ellos se hiciera una lámpara y se dotara de aceite para la capilla de Nuestra Señora de Gracia del Convento de San Agustín. Ahora bien, con respecto al legado efectuado al convento carmelita se especifica lo siguiente:

14 AGI. Testamento de Damián Ruiz de Salazar. Contratación, 253, № 7 . 


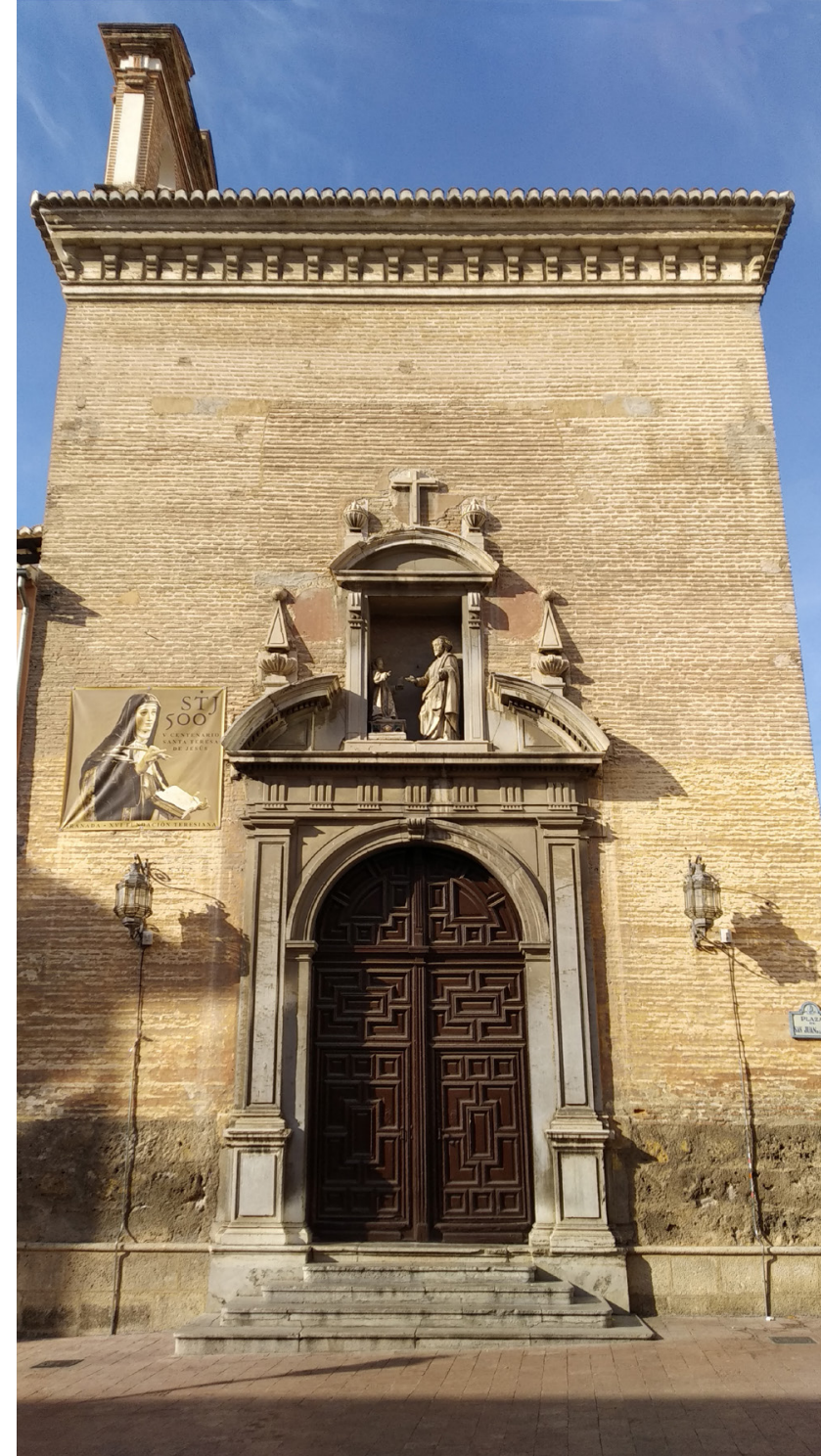

Fig. 2: Exterior del convento de San José en Granada
Ytem, mandamos a Damian (sic) Nuñez de Salazar, prima del difunto, çien ducados de Castilla puestos en la dicha çiudad de Granada a riesgo y quenta de la susodicha y a costa del dicho difunto, y si la susodicha fuere muerta los aya y herede doña Luisa de Buenaventura, monja profesa en el monasterio de las carmelitas descalzas de la dicha çiudad para que por ella los aya el dicho convento y se destribuyan (sic) en las cosas más necesarias del ornato de la sacristía del dicho convento. Ytem, mandamos al convento de carmelitas descalças de la dicha çiudad de Granada çinquenta ducados para que los distribuyan en las cosas más necesarias del dicho convento"15.

Quizás la donación se efectuara por conocer a una de las monjas profesas del citado convento, la referida doña Luisa de Buenaventura, aunque desconocemos si entre ellos había alguna relación de parentesco como era lo habitual en estos casos. No obstante, lo que queda patente es la necesidad económica del convento lo que se desprende al destinarse en otra partida 50 ducados a las cosas más urgentes, sin un propósito o finalidad concreta.

Otro convento de importancia en la ciudad será el de los Santos Mártires fundado en 1573 en memoria de los Santos Cosme y Damián. Este se emplazó en la parte más alta del barrio de la Antequeruela, en el área donde se encontraba la Ermita de los Mártires erigida por los Reyes Católicos y cuya administración dependía de la Capilla Real ${ }^{16}$. Desaparecido paulatinamente tras la desamortización poco conocemos acerca de su historia constructiva y artística, no obstante, valgan las palabras de Henríquez de Jorquera sobre el convento, palabras que tomamos con la prudencia que debe atenderse a las crónicas históricas: "vistoso y agradable, labrado a lo moderno con buenas capillas, claustro y oficinas"17. Sin embargo, se conserva una vista del convento, con su claustro, terreno agrícola acotado y el templo, perfectamente representados en la Plataforma de Ambrosio de Vico, primera vista topográfica de Granada, bastante cercana a la realidad, abierta a buril por Francisco Heylan en $1613^{18}$ (Fig. 3), cuyo objetivo era integrarse como ilustración de la Historia Eclesiástica

15 Ibid

16 GÓMEZ-MORENO CALERA, J. M.: La arquitectura religiosa granadina en la crisis del Renacimiento (1560-1650). Monografía Arte y Arqueología, Vol. 4. Granada, Universidad de Granada y Diputación Provincial de Granada, 1989, pp. 236

17 HENRÍQUEZ DE JORQUERA, F.: Anales de Granada: descripción del reino y ciudad de Granada. Cronica de la reconquista (1482-1492). Sucesos de los años 1588 à 1646.2 vols. Granada, Publicaciones de la Facultad de Letras, 1934, p. 628

18 MORENO GARRIDO, A.; GÓMEZ-MORENO, J. M. y LÓPEZ GUZMÁN, R.: "La Plataforma de Ambrosio de Vico: Cronología y Gestación", Revista del Colegio de Arquitectos de Andalucía Oriental (Granada), 1984, número 1, pp. 6-11. 


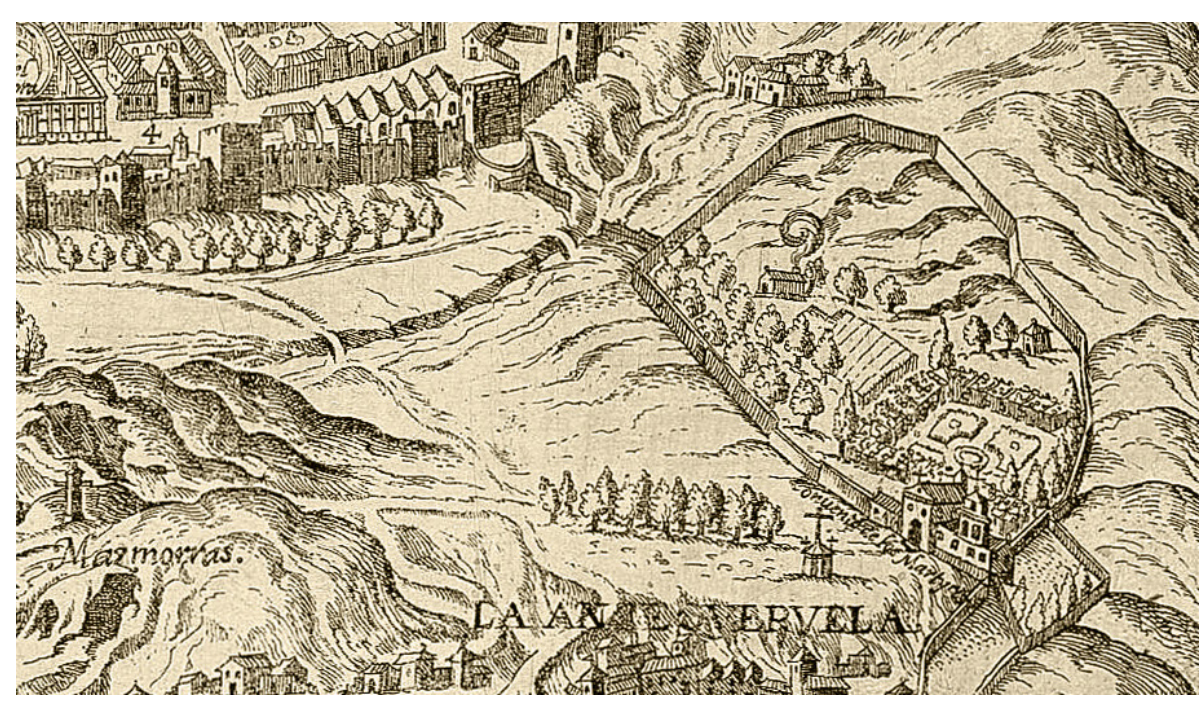

3: Detalle del emplazamiento del convento de los Santos Mártires de Granada. Plataforma de Vico, grabada por Heylan, 1613. @ Ayuntamiento de Granada, Archivo Municipal de Granada

de Granada de Justino Antolínez de Burgos, la cual no se imprimiría hasta 1996, aunque sus láminas se conocieron desde su realización y se hicieron copias de muchas de ellas. Con mayor grado de definición aparece en el plano topográfico de Francisco Dalmau de 1796 (Fig. 4).

A este convento carmelita destinará Pedro Galera, difunto en Guadalajara (Nueva España), la cantidad de 22.000 pesos más 334 pesos y 4 tomines en plata. Este indiano era vecino de la Villa de Llerena e hijo de Pedro Galera Arias y de Juana de Palacios, naturales de Granada. En su testamento dejó constancia de que un pariente suyo, fraile carmelita descalzo de esta ciudad, le solicitó en una carta que hiciera una fundación pía, solicitud que él aceptó haciendo donación de la hacienda que tenía en la ciudad (de la cual desconocemos su alcance), prometiendo además la cantidad reseñada con anterioridad que cataloga por bienes eclesiásticos, para que de este modo los cobrara más fácilmente su primo fray Ángel (quien pensamos fue quien se puso en contacto con él) o cualquier otro conventual ${ }^{19}$.

19 AGI. Testamento de Pedro Galera. Contratación, 401, № 1, folio 6r-8v.

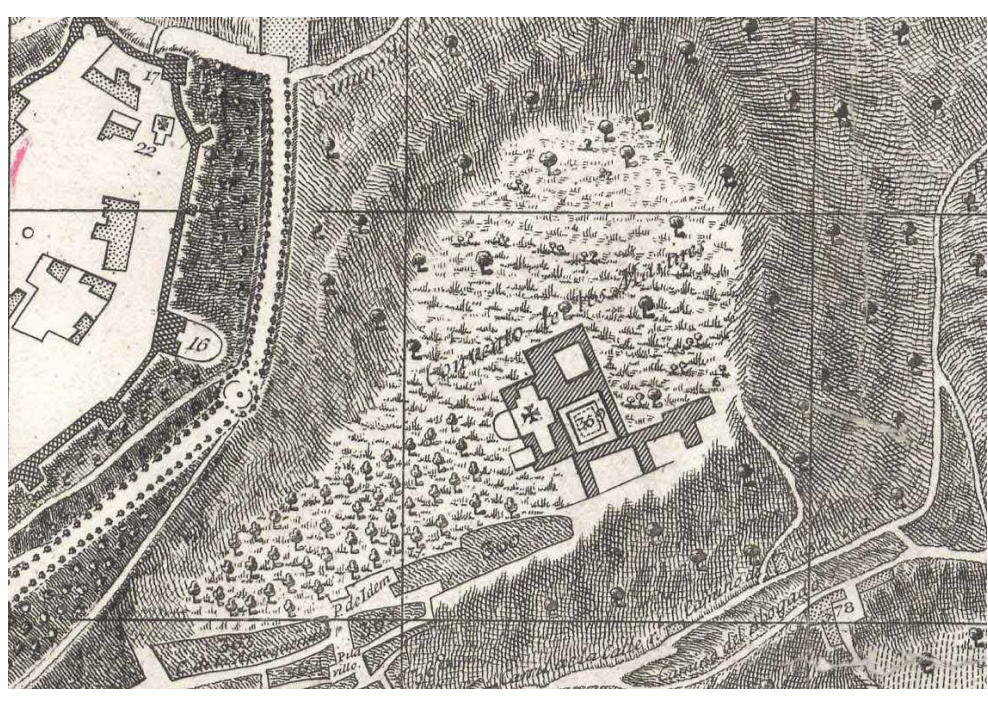

Fig. 4: Detalle del emplazamiento del Convento de los Santos Mártires de Granada. Plano de Dalmau, grabado por Ribera, 1796. ๑ Ayuntamiento de Granada. Archivo Municipal de Granada

“(Al margen:) Manda para Castilla.

Ytem, declaro que por quanto yo tengo comunicado por cartas con un pariente mío, frayle carmelita descalso que reside en la çiudad de Granada, se haga çierta fundaçión pía, para cuio efecto he hecho donaçión de cantidad de hazienda que en la dicha çiudad de Granada tengo, e para más aumento del serviçio de Dios he prometido otros veynte y dos mil pesos //7r de los bienes que acá Dios me a dado, por tanto digo que e hago e señalo por bienes eclesiásticos la dicha cantidad de los veynte y dos mil pesos..."

El testamento lo otorgó en la ciudad de Zacatecas el 1 de septiembre de 1620, no obstante, no hay constancia de la llegada de parte de este legado al menos hasta el 20 de diciembre de 1639 en el que desde el Convento de los Santos Mártires se certifica la donación ${ }^{20}$, que se recibiría en la Casa de Contratación de Sevilla dos meses más tarde de la mano de fray Juan de San Bernardo, rector del Colegio del Ángel por orden del prior ${ }^{21}$.

20 AGI. Herederos de Pedro Galera sobre cobrar sus bienes, 401, № 1, folio 3r.

21 AGI. Notificación de entrega de los bienes de Pedro Galera por parte de la Casa de Contratación, 401, No 1 , folio $10 \mathrm{r}$. 


\section{JUAN DE LA TORRE Y EL CONVENTO DEL SANTO ÁNGEL CUSTODIO} DE SEVILLA

El convento fue fundado en 1587 por San Juan de la Cruz, construyéndose entre 1603 y 1608, siguiendo los planos del arquitecto Alonso de Vandelvira (fig. 5). Desde que se levantara siempre ha pertenecido a la Orden Carmelita, conservándose hoy día en su interior un rico patrimonio, lo que la convierte en una joya de la arquitectura sevillana. Consta de tres naves con un crucero poco pronunciado, estando cubierta la nave central con bóveda de cañón y las laterales de arista. Al igual que sucedió en el convento de San José de Granada, poco tiempo después de su fundación recibió una importante herencia de la mano de un indiano natural de la provincia de Cádiz. Este andaluz, llamado Juan de la Torre, había nacido en Sanlúcar de Barrameda y era hijo de Andrés de la Torre y Beatriz del Águila, a quienes legó en principio todo su patrimonio, quizás por no tener descendencia. El testamento, que firma en Sevilla el 17 de febrero de 1589 ante el escribano público Juan de Velasco ${ }^{22}$, es de enorme interés pues contiene toda una serie de voluntades y directrices que afectarán al devenir de dicho convento, convertido finalmente en el único heredero de sus bienes tras su fallecimiento y la muerte de sus progenitores. De hecho, tenemos constancia de que cuatro años más tarde, concretamente el 25 de agosto de 1593, fray Nicolás de San Juan, actuando en nombre del colegio de carmelitas descalzos de Sevilla, tuvo noticias de que los bienes habían llegado por fin desde Nueva España en tres partidas diferentes contenidas en el registro, por lo que no tardarían en percibir las cantidades asignadas ${ }^{23}$.

Como ya advertimos anteriormente, un proceso muy común entre los andaluces retornados de América era fundar una capilla con bóveda de enterramiento en algún templo de la ciudad, de esta manera se facilitaba su "tránsito" a la nueva vida, quedando de manifiesto su sentimiento piadoso. Juan de la Torre hará lo propio para que tras su fallecimiento los receptores de sus bienes se ocuparan de dar cumplimiento a este deseo de contar con un espacio propio en el que ser enterrado y recordado en el interior del mencionado convento, a pesar de que sus progenitores contaban ya con una capilla propia en el Monasterio de Nuestra Señora de las Mercedes en la capital hispalense. Para conseguir este fin establece una cláusula por la que obliga a los frailes a ejecutar la capilla en el plazo de dos años desde que tomaran posesión de sus bienes, debiendo estar ubicada a un lado del altar mayor, en el lugar que mejor les pareciere, y una vez ejecutada la bóveda darle enterramiento solemne, como luego se verá.

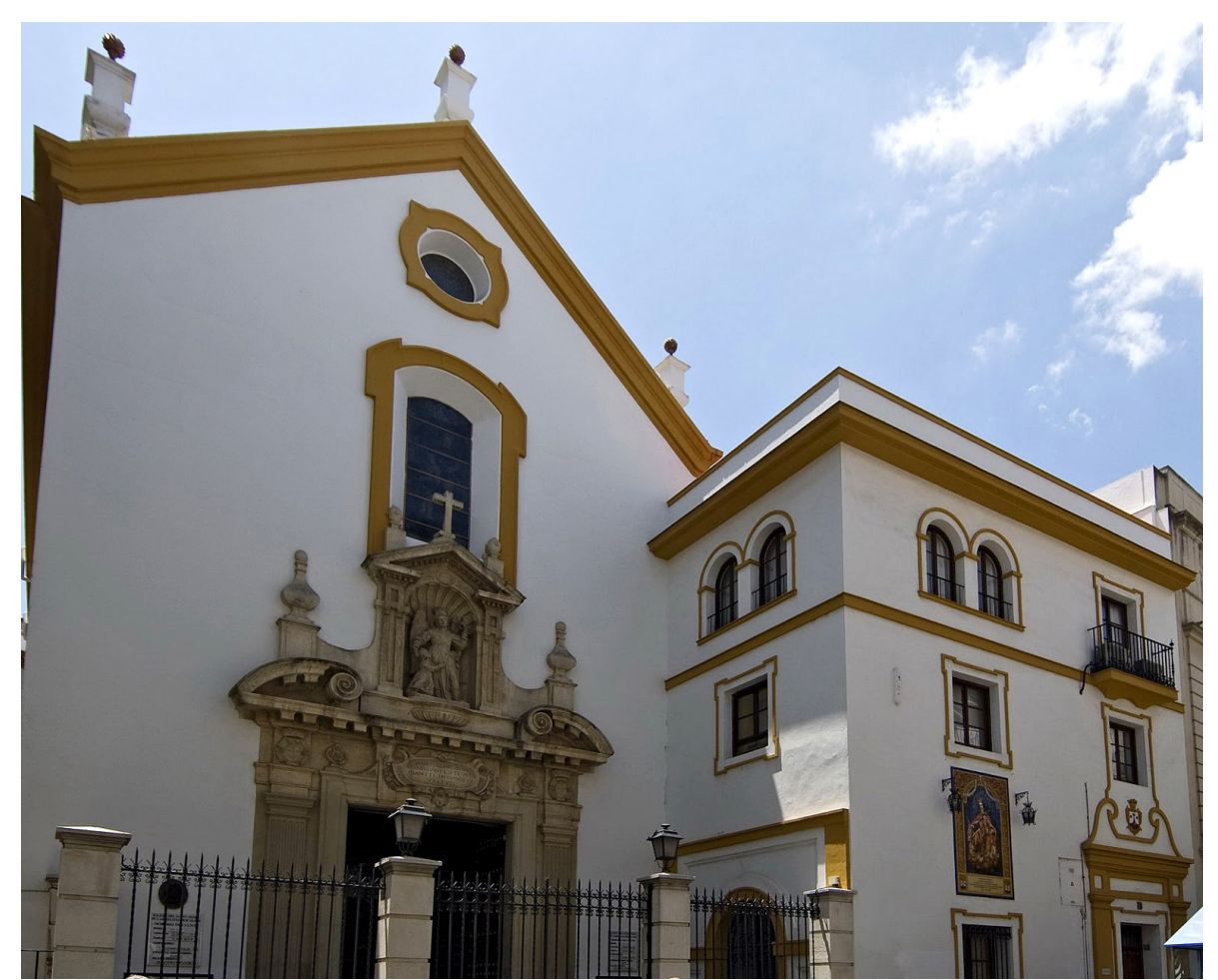

Fig. 5: Exterior del convento del Santo Ángel Custodio en Sevilla 
En el interior de la capilla se debía hacer un altar en el que se realizaría un retablo en el que se colocarían las siguientes imágenes: "Nuestro Señor Jesucristo Crusificado e Nuestra Señora e San Juan y los dos san Juanes, Vautista y Evangelista, e San Cosme e San Damián //8r e San Gregorio e San Benito e Santo Domingo, de figuras pequeñas al ólio, pintado todo ello en tabla o de vulto, como a los dichos frayles les paresiere"24. Este retablo debía permanecer perpetuamente en su interior, así como su cuerpo, que únicamente podía trasladarse en el caso de que el colegio carmelita cambiara de emplazamiento. Para proteger la capilla se debía poner una reja de madera o de hierro, además de una cartela en la que figurara la leyenda "Esta capilla y entierro es de Juan de la Torre y sus herederos". En caso de que finalmente se hiciera el mencionado desplazamiento especifica que los costes del cambio de ubicación y del levantando la nueva capilla y bóveda debían asumirlo los frailes, colocando el altar y retablo de nuevo en su interior y eligiendo para este fin algunos de los espacios inmediatos al altar mayor.

Para asegurar la materialización de su capilla establece como requisito que desde el día en que ésta se empezara a labrar los frailes debían pagar a su primo, también llamado Juan de la Torre, veinte ducados cada año hasta que no se terminara completamente, incluyéndose el retablo y la reja. Una vez cumplida su voluntad esta obligación quedaría anulada. No obstante, existían otros condicionantes como, por ejemplo, la posibilidad de que en la mencionada capilla pudieran enterrarse todos sus deudos y parientes por parte de padre y de madre; la obligatoriedad de que los frailes casaran a una doncella cada año y de manera perpetua (este requisito se ejecutaría de forma rotativa, pues el primer año se debía celebrar en su capilla, al siguiente en el Monasterio de Madre de Dios de monjas de su tierra natal y el tercero en la capilla de sus padres, y así sucesivamente) ${ }^{25}$; la imposición de que los frailes, una vez poseyeran sus bienes, le dijeran en el convento por su alma y la de sus padres, las nueve fiestas de Nuestra Señora con sus vísperas, misa cantada y responso; y, por último, la obligación de que éstos les dijeran en el Monasterio de Nuestra Señora de las Mercedes, entendemos que en la capilla de sus progenitores:

“... unos todosantos y fiestas de finados [...] poniendo su tunva en la dicha capilla con un paño negro //9r cubierta, e seis hachas de será blanca enfendidas (sic), que duren mientras duran los oficios encendidas, e que hagan salir veynte y quatro frailes del dicho monasterio y al fin de la misa..."26.

4 AGI. Testamento de Juan de la Torre. Contratación, 924B, no 19 , folios 7v-8

25 Como ayuda al matrimonio destinarían veinte mil maravedís como dote, procedente de la renta de su
Juan de la Torre al no tener certeza de que los frailes fueran a aceptar los términos del testamento y, por tanto, la herencia, deja abierta la posibilidad de que, en caso de negativa sea el Monasterio de Nuestra Señora de las Mercedes el beneficiario. En este caso los condicionantes serán más suaves puesto que la obligación de realizar una capilla con bóveda de enterramiento quedaba sin ejecución al poderse utilizar la que poseían allí sus padres y que por derecho de sucesión también le pertenecía. No obstante, deja por escrito que en este caso se debía ornamentar el espacio colocando un retablo bajo la advocación de la Adoración de los Tres Reyes Magos, y quitar tres confesionarios que en ella había, aderezándolos de manera que el espacio quedara libre.

Por último, quedaba pendiente el asunto de su entierro, para ello especifica que en caso de fallecer en Sevilla, como así ocurrió, debían los frailes darle sepultura en el convento hasta que, una vez construida su capilla, sus restos mortales fueran trasladados a ésta. No obstante, en caso de fallecer en algún otro lugar debían ser sus albaceas los que, a costa de sus bienes, se hicieran cargo del traslado del cuerpo hasta la ciudad hispalense con la pompa y el acompañamiento que le pareciera a los rectores del colegio, procediendo los frailes a su enterramiento de la manera descrita. Su muerte tuvo lugar el 4 de enero de 1693 y de su enterramiento en el colegio de los carmelitas descalzos dio testimonio la Casa de Contratación por una carta fechada el 26 de agosto del mismo año ${ }^{27}$. Así, también hemos podido certificar algunas partidas de dinero que fue llegando de Nueva España y que como avanzamos, fray Nicolás se encargará de reclamar por los procedimientos regulares: 152 pesos de oro común que vino en la nao denominada San Gregorio capitaneada por el maestre Pedro Sánchez de Figueroa, incluida en una partida total de 352 pesos del mismo metal; 140 pesos de oro común, incluidos en una partida de 356 pesos, que vino en la nao llamada de San Antonio del maestre Francisco de Valverde; y 577 pesos y cuatro tomines que se recibieron de la nao nombrada de Nuestra Señora del Rosario ${ }^{28}$. Las tres partidas fueron entregadas por autoridades de la Casa de Contratación al convento, según consta por registro y cartas de pago $^{29}$

herencia. Ahora bien, en el caso de que la mujer que se casara fuera de su linaje se le multiplicaría el importe, pagándosele tres años el importe íntegro de esa renta y hasta que no se abonaran completamente no se permitía el casamiento de ninguna otra mujer.

26 AGI. Testamento de Juan de la Torre. Contratación, 924B, nº 19, folios 8v-9r.

27 AGI. Notificación de la Casa de Contratación. Contratación, 924B, nº 19, folio $11 \mathrm{r}$.

28 AGI. Notificación de las partidas de dinero procedente de Nueva España. Contratación, $924 \mathrm{~B}, \mathrm{n}^{\circ}$ 19, folio $14 \mathrm{r}$.

9 AGI. Notificación de la Casa de Contratación. Contratación, 924B, nº 19, folios 3r-3v, 4r-4v y 5r-5v 
Desconocemos si el mandato de Juan de la Torre finalmente se realizó o si se cumplieron algunos de los requisitos fijados en su testamento para que los frailes percibieran la abultada herencia, lo que sí podemos atestiguar es que a día de hoy no hay ninguna referencia a este indiano en la historia del convento ni hemos localizado ningún indicio que nos lleve a pensar en la existencia o desaparición de su capilla. De hecho, al igual que ocurriera con las donaciones de otros muchos andaluces a templos e iglesias a los pueblos o ciudades con los que estaban vinculados, en este caso solo podemos aportar referencias documentales. Referencias que, por otra parte, son fundamentales para poder entender el impacto económico y social que tuvo el descubrimiento y la administración de los territorios americanos en Andalucía.

\section{CONCLUSIONES}

Los legados de Damián Ruiz de Salazar y Pedro Galera a los conventos carmelitas de la ciudad de Granada y el de Juan de la Torre al Convento del Santo Ángel Custodio de Sevilla, son solo una pequeña muestra de las donaciones que presumiblemente se enviaron a otras muchas instituciones religiosas por parte de indianos afincados en diferentes partes de América. De hecho, la huella de América en nuestras ciudades es más que manifiesta, en forma de cuadros de procedencia en su mayoría anónima que representan fundamentalmente devociones marianas americanas, como fue la Virgen de Guadalupe o Santa Rosa de Lima. Este hecho además es visible a través de una gran cantidad de objetos de platería americana que atesoran las instituciones religiosas y de las cuales se desconoce igualmente el origen de la mayor parte de ellos. Si a esto unimos la rica documentación histórica conservada en archivos de protocolos notariales y en el Archivo General de Indias, como los más señeros en este campo, nos daremos cuenta de la magnitud de este campo de estudio y de todo lo que aún queda por hacer en el ámbito del mecenazgo indiano. Sin duda, la labor más ardua será la reconstrucción de las relaciones existentes entre los legados enviados y los objetos que actualmente se conservan, siendo conscientes de que solo una mínima parte de las obras que se enviaron desde Indias existen hoy. 


\section{BIBLIOGRAFÍA}

DEDIEU, J. P.: "El séquito de los obispos que pasaron a Indias en la primera mitad del siglo XVIII", en AGUIRRE, R. y ENRÍQUEZ, L., La iglesia hispanoamericana de la Colonia a la República. México, Universidad Nacional Autónoma de México y Pontificia Universidad de Chile, 2008, pp. 203-230. http://halshs.archives-ouvertes.fr/halshs-00105935 (consulta 5 de Abril de 2017).

ESPINOSA SPÍNOLA, G. y ROMERO SÁNCHEZ, G.: "Riquezas de Indias en Andalucía: poder, dinero y promoción artística. Aproximación a un estado de la cuestión", en ALON SO RUIZ, B; POLO SÁNCHEZ, J. y SAZATORNIL RUIZ. L. (coords.): La formación artística: creadores - historiadores - espectadores. XXI Congreso Nacional de Historia del Arte. Santander, Editorial Universidad de Cantabria, 2018, pp. 1421-1432.

ESTERAS MARTÍN, C.: "Nuevas aportaciones a la historia de la platería andaluza-americana”, en TORRES RAMÍREZ, B. y HERNÁNDEZ PALOMO, J. J. (coords.): Andalucía y América, siglo XVII. Actas III Jornadas de Andalucía y América. Huelva, La Rábida, 1985 tomo 2, pp. 31-58.

GARCÍA-ABASOLO GONZÁLEZ, A. F.: "Inversiones indianas en Córdoba. Capellanías y patronatos como entidades financieras”, en TORRES RAMÍREZ, B. y HERNÁNDEZ PALOMO, J. J. (coords.): Andalucía y América, siglo XVI. Actas II Jornadas de Andalucía y América. Huelva, La Rábida, 1982, tomo 2, pp. 427-454.

GÓMEZ-MORENO CALERA, J. M.: La arquitectura religiosa granadina en la crisis del Renacimiento (1560-1650). Granada, Universidad de Granada y Diputación Provincial de Granada, 1989.

GONZÁLEZ GÓMEZ, J. J.: "El convento de San Juan Bautista de Villalba del Alcor, una fundación indiana de 1618”, en TORRES RAMÍREZ, B. y HERNÁNDEZ PALOMO, J. J. (coords.): Andalucía y América, siglo XVII. Actas III Jornadas de Andalucía y América. Huelva, La Rábida, 1982, tomo 2, pp. 81-96.

HENRÍQUEZ DE JORQUERA, F.: Anales de Granada: descripción del reino y ciudad de Granada Crónica de la reconquista (1482-1492). Sucesos de los años 1588 à 1646. 2 vols. Granada, Publicaciones de la Facultad de Letras, 1934.
LÓPEZ GUZMÁN, R. y ESPINOSA SPÍNOLA, G.: América con tinta andaluza. Historia del arte e historiografía. Almería, Servicio de Publicaciones de la Universidad de Almería, 2013.

LÓPEZ GUZMÁN, R. y ROMERO SÁNCHEZ, G. "El Convento de San Antón y el Mecenazgo Indiano”, Entre Ríos. Revista de Arte y Letras, vol. 21-22, 2014, pp. 98-108.

MENSAQUE URBANO, J.: "El mecenazgo artístico del indiano Alonso González de la Pava en Guadalcanal”, en TORRES RAMÍREZ, B. y HERNÁNDEZ PALOMO, J. J. (coords.): Andalucía y América, siglo XVII. Actas III Jornadas de Andalucía y América. Huelva, La Rábida, 1982, tomo 2, pp. 59-80.

MONTES GONZÁLEZ, F.: Mecenazgo virreinal y patrocinio artístico. El ducado de Alburquerque en la Nueva España. Sevilla, Real Maestranza de Caballería de Sevilla, 2016.

MORALES FOLGUERA, J. M.: "Los Gálvez de Macharaviaya y la ilustración americana". LÓPEZ GUZMÁN, R. (coord.): Andalucía-América. Estudios artísticos y culturales. Granada, Editorial de la Universidad de Granada y Atrio, 2010, pp. 111-135.

MORALES MARTÍNEZ, A. J.: "Presencia del arte barroco mexicano en Andalucía", en LÓPEZ GUZMÁN, R. (coord.): Andalucía y América. Cultura artística. Granada, Editorial Atrio, pp.13-29.

MORENO GARRIDO, A.; GÓMEZ-MORENO, J. M. y LÓPEZ GUZMÁN, R.: "La Plataforma de Ambrosio de Vico: Cronología y Gestación”, Revista del Colegio de Arquitectos de Andalucía Oriental, vol. 1, 1984, pp. 6-11.

QUILES GARCÍA, F.: Sevilla y América en el barroco. Comercio, ciudad y arte. Sevilla, Bosque de Palabras, 2009.

RODRÍGUEZ MOYA, I.: La mirada del Virrey. Castellón, Universidad Jaume I, 2003.

ROMERO SÁNCHEZ, G. y ESPINOSA SPÍNOLA, G.: "El mecenazgo indiano en Andalucía oriental: el caso de don Luis Pérez Navarro", en RODRÍGUEZ MOYA, I., FERNÁNDEZ VALLE, M. A. y LÓPEZ CALDERÓN, C (coords.): Arte y patrimonio en Iberoamérica. Tráficos transoceánicos. Castellón, Servicio de Publicaciones de la Universitat Jaume I, 2016, pp. 233-253 
ROMERO SÁNCHEZ, G.: “Tesoros viajeros. Mecenazgo y coleccionismo artísticos en Andalucía”. Desde América del Sur. Arte virreinal en Andalucía. Catálogo de la Exposición. Granada, Proyecto MUTIS, 2017, pp. 47-50.

RUIZ GUTIÉRREZ, A.: Fray Alonso de Montúfar: Loja y la formación de la iglesia indiana Granada, Fundación Ibn al-Jatib de estudios y cooperación cultural, 2007. 